\title{
One size does not fit all... Panel data: Bayesian model averaging and data poolability
}

\author{
Rodolphe Desbordes* Gary Koop ${ }^{\dagger}$ Vincent Vicard ${ }^{\ddagger}$
}

\begin{abstract}
We show in this paper why researchers ought to pay particular attention to the issues of model uncertainty and data poolability in their panel data applications. We focus on the identification of robust determinants of current account balances (CABs). Applying Bayesian Model Averaging, we adopt a flexible modelling approach to highlight that (i) some determinants have limited relevance when accounting for model uncertainty; (ii) slope homogeneity is unlikely to be a valid assumption; iii) cross-sectional and time-series relationships can diverge. We explain why estimating cross-sectional estimates is valuable, even in the potential presence of an omitted variable bias, and suggest a way for assessing the effects of unobserved country heterogeneity.
\end{abstract}

Keywords: Bayesian model averaging; current account; heterogeneity; panel data; poolability.

JEL Classification: F32, C11, C21, C23

Word count: 7562

*Corresponding author, SKEMA-UCA. E-mail: rodolphe.desbordes@ @kema.edu. Mail: SKEMA Paris, La Défense Campus, Pôle Universitaire Léonard de Vinci, Esplanade Mona Lisa, Courbevoie, 92916 Paris La Défense Cedex, France. Phone: +33 (0)1 41167461 .

${ }^{\dagger}$ Strathclyde university, E-mail: gary.koop@strath.ac.uk

${ }^{\ddagger}$ CEPII, E-mail: vincent.vicard@cepii.fr 


\section{Introduction}

Martin Wolf, in his book 'The Shifts and the Shocks', describes the global financial crisis and the more recent Eurozone crisis as being the immediate consequences of global and regional current account imbalances (Wolf, 2014). This interpretation is widely shared among economists and has led to a resurgence of interest in identifying the determinants of current account balances (CABs) and then calculating deviations of the actual CABs from benchmark values. ${ }^{1}$ However, the theoretical and empirical literature has not reached a consensus on the key determinants of CABs yet. The standard intertemporal approach to the current account casts the $\mathrm{CAB}$ as generated by deviations of output, investment, and government spending from their long-run averages (Obstfeld and Rogoff, 1995). Empirical applications have extended those basic determinants to typically include country characteristics such as demography, relative income per capita, net foreign asset position, mineral resources, as well as global determinants such as risk aversion, revisions to growth expectations, oil prices or foreign reserves accumulation following the 1997/98 Asian crisis (Bernanke, 2013). The recent literature also assigns a central role to asymmetries in financial development/frictions (Caballero et al., 2008; Chinn and Ito, 2007), financial excesses through leveraging (Chinn et al., 2014), housing prices/investment (Aizenman and Jinjarak, 2009) or asset prices (Fratzscher and Straub, 2009), and income volatility and uncertainty (Fogli and Perri, 2006). Valuation effects, expected or unexpected, may also matter to explain CABs (Gourinchas and Rey, 2014). In practice, the statistical and economic relevance of potential determinants of CABs appears to be a function of researchers' focus, countries included in the sample, and model specification. ${ }^{2}$

The purpose of this paper is to use the specific exploration of the 'robust' determinants of CABs to more broadly demonstrate that researchers ought to take seriously the issues of model uncertainty and data poolability in their panel data applications. In presence of weak theoretical guidance and a large number of potentially relevant determinants, a natural response to model uncertainty is to estimate various econometric models in order to find the 'best' model. This is usually done in the empirical literature in an unsatisfactory manner. Typically, an initial model is selected and then 'tweaked' by adding or removing some variables based on tests of statistical significance. With such an approach, the researcher leaves almost all of the potential models unexplored and ignores the econometric issues associated with sequential testing. We use

\footnotetext{
${ }^{1}$ See e.g. Lane and Milesi-Ferretti (2012) or Chinn et al. (2014).

${ }^{2}$ Ciocyte and Rojas-Romagosa (2015) provide an excellent survey of the literature. Chinn and Prasad (2003) is a typical empirical study in this field.
} 
Bayesian Model Averaging (BMA) to handle model uncertainty in a more satisfactory and theoreticallygrounded approach. Consistent with Bayesian theory, BMA involves obtaining results from all possible models and averaging them. Furthermore, our BMA implementation explicitly accounts for the fact that data poolability may not be a valid assumption. We allow for slope heterogeneity across data dimensions and country groups, by decomposing the panel data in cross-sectional (between) and time-series (within) dimensions and distinguishing between various groups of countries. Last but not least, we propose a method to assess a potential omitted variable bias in a cross-sectional setting.

Our results show that many variables perceived as robust determinants in the literature are not relevant across models and the CABs of OECD and non-OECD countries do not respond in the same way to a given variable. We also find that cross-sectional and time-series relationships can differ. While we cannot rule out that the 'between' estimates are contaminated by an omitted variable bias, we show that their estimation is still valuable for predictive purposes. Furthermore, our combination of BMA and ridge regression methods, which allows us to include country fixed effects in a cross-sectional setting, suggests that some of the 'between’ estimates may reflect a causal relationship. Overall, our results highlight the need for the flexible modelling approach that we implement.

Two recent papers are closely related to our empirical application: Ca Zorzi et al. (2012) and MoralBenito and Roehn (2016). Both use BMA to investigate the determinants of the CAB. However, we depart from their analyses in several ways. Our country coverage is broader and we investigate in more depth the issue of data poolability. In our modelling approach, we draw a sharper and more explicit distinction between short-run and long-run determinants of $\mathrm{CAB}$ and account explicitly for cyclical determinants of the CAB using higher frequency data. We also contribute to an older literature (e.g. Chinn and Prasad (2003)) which proposes to draw inferences from a cross-sectional analysis. Beyond the topic of CABs, our work is linked to the debate in Political Science on how to deal with (quasi-) time-invariant variables in a panel data setting (e.g. Bell and Jones (2015), Clark and Linzer (2015)) by putting forward a way to check for the presence of unobserved country heterogeneity.

The rest of the paper proceeds in the following way. We explain in Section 2 why inferences may vary according to the panel data estimator used. We describe in Section 3 the implementation of BMA in a panel data context. We present in Section 4 the results of our empirical application. We examine in Section 5 the usefulness of our BMA exercise for both prediction and normative evaluation. We tackle in Section 6 the 
issue of country heterogeneity in a cross-sectional context. Section 7 concludes.

\section{Panel data estimators}

Panel data combine a cross-sectional dimension with a time-series dimension. ${ }^{3}$ We have $T$ data points ${ }^{4}$ for $i=1, . ., N$ countries and we are interested in estimating the regression model

$$
y_{i t}=\beta_{0}+x_{i t} \beta+\epsilon_{i t}
$$

where $y_{i t}$ is the dependent variable, $x_{i t}$ are explanatory variables, and $\epsilon_{i t}$ is the error term. The OLS estimator of $\beta$ can be written as

$$
\begin{aligned}
b^{\text {total }} & =\left[S_{x x}^{\text {total }}\right]^{-1}\left[S_{x y}^{\text {total }}\right] \\
& =\left[S_{x x}^{\text {within }}+S_{x x}^{\text {between }}\right]^{-1}\left[S_{x y}^{\text {within }}+S_{x y}^{\text {between }}\right]
\end{aligned}
$$

where the total sum of squares $S_{x x}^{\text {total }}$ equals the within-groups sums of squares and the between-groups sums of squares (with bars over variables denoting averages):

$$
\begin{aligned}
\sum_{i=1}^{N} \sum_{t=1}^{T}\left(x_{i t}-\bar{x}\right)^{2} & =\sum_{i=1}^{N} \sum_{t=1}^{T}\left(x_{i t}-\overline{x_{i}}\right)^{2}+\sum_{i=1}^{N}\left(\overline{x_{i}}-\bar{x}\right)^{2} \\
S_{x x}^{\text {total }} & =S_{x x}^{\text {within }}+S_{x x}^{\text {between }}
\end{aligned}
$$

and the total sum of cross-products $S_{x y}^{t o t a l}$ equals the within-groups sums of cross-products and the betweengroups sums of cross-products:

$$
\begin{aligned}
\sum_{i=1}^{N} \sum_{t=1}^{T}\left(x_{i t}-\bar{x}\right)\left(y_{i t}-\bar{y}\right) & =\sum_{i=1}^{N} \sum_{t=1}^{T}\left(x_{i t}-\overline{x_{i}}\right)\left(y_{i t}-\overline{y_{i}}\right)+\sum_{i=1}^{N}\left(\overline{x_{i}}-\bar{x}\right)\left(\overline{y_{i}}-\bar{y}\right) \\
S_{x y}^{\text {total }} & =S_{x y}^{\text {within }}+S_{x y}^{\text {between }} .
\end{aligned}
$$

\footnotetext{
${ }^{3}$ This section heavily draws on Greene (2008, chapter 11 ).

${ }^{4}$ With an unbalanced panel, trivial modifications of the formulae below are required.
} 
A regression model can also be formulated in terms of the group means

$$
\bar{y}_{i}=\beta_{0}+\bar{x}_{i} \beta^{\text {between }}+\bar{\epsilon}_{i}
$$

with OLS 'between' estimator $b^{\text {between }}=\left[S_{x x}^{\text {between }}\right]^{-1} S_{x y}^{\text {between }}$. In addition, a regression model can be written for the group deviations:

$$
\left(y_{i t}-\bar{y}_{i}\right)=\left(x_{i t}-\bar{x}_{i}\right) \beta^{\text {within }}+\left(\epsilon_{i t}-\bar{\epsilon}_{i}\right)
$$

with OLS 'within' estimator $b^{\text {within }}=\left[S_{x x}^{\text {within }}\right]^{-1} S_{x y}^{\text {within }}$. This implies that the pooled OLS estimator is a matrix weighted average of the within estimator and the between estimator:

$$
b^{\text {total }}=F^{\text {within }} b^{\text {within }}+F^{\text {between }} b^{\text {between }}
$$

with $F^{\text {within }}=\left[S_{x x}^{\text {within }}+S_{x x}^{\text {between }}\right]^{-1}\left[S_{x y}^{\text {within }}=I-F^{\text {between }}\right.$.

This decomposition of the pooled OLS estimator into its between and within components highlights that it is often not easy to draw inferences from pooled OLS estimates, given that they are by nature averages of the potentially heterogeneous 'between' and 'within' estimates. For example, the within estimates and between estimates would diverge if the true model is not static but dynamic. In that case, under some conditions, the within estimator would tend to reflect the short-run effects while the between estimator would provide a reasonable approximation of the long run effects (Baltagi and Griffin, 1984; Pesaran and Smith, 1995; Pirotte, 1999, 2003; Egger and Pfaffermayr, 2005; Pirotte and Mur, 2017). Such an interpretation is common in applied economics and well-grounded in economic theory. ${ }^{5}$

Distinguishing between short-run and long-run effects is one reason why researchers, including in the CAB literature (e.g. Chinn and Prasad (2003)), often favour estimating models (2) and (3) over simply estimating model (1). Another reason is that the error term $\epsilon_{i t}$, may include a time-invariant country-

\footnotetext{
${ }^{5}$ For example, Pirotte and Mur (2017) conclude "To summarize, the Between and Within estimators obtained in a static panel data model constitute, in general terms, reliable approximations of the long- and short-run effects, respectively" (p.227).
} 
specific effect $c_{i}$ (unobserved country heterogeneity) correlated with the explanatory variables. Given that this specific omitted variable bias disappears when model (3) is considered, some researchers are more confident that they uncover causal relationships when using the within estimator. However, as discussed previously, other misspecifications can generate differences in the between and within estimates (Egger and Pfaffermayr, 2002).

The 'between' and 'within' estimates can be simultaneously obtained by using a correlated random effects (CRE) approach, where the dependence between unobserved country heterogeneity $c_{i}$ and the explanatory variables is explicitly specified such as $c_{i}=\alpha+\bar{x}_{i} \gamma+r_{i}$, with $r_{i}$ assumed to be uncorrelated with $x_{i t}$ :

$$
\begin{aligned}
& y_{i t}=x_{i t} \beta+c_{i}+u_{i t} \\
& y_{i t}=\alpha+x_{i t} \beta+\bar{x}_{i} \gamma+r_{i}+u_{i t} \\
& y_{i t}=\alpha+x_{i t} \beta^{C R E}+\bar{x}_{i} \gamma^{C R E}+v_{i t}
\end{aligned}
$$

where $v_{i t}$ is a composite error term. The random effects estimator should be used to deal with the serial correlation in $v_{i t}$ induced by $r_{i}$. Mundlak (1978) shows that $\beta^{C R E}=\beta^{\text {within }}$ and $\gamma^{C R E}=\beta^{\text {between }}-\beta^{\text {within }}$. These equivalences can be made more explicit by using $x_{i t}=x_{i t}-\bar{x}_{i}+\bar{x}_{i}$ and re-writing equation (4) such as

$$
\begin{aligned}
& y_{i t}=\alpha+\left(x_{i t}-\bar{x}_{i}\right) \beta^{C R E}+\bar{x}_{i}\left(\gamma^{C R E}+\beta^{C R E}\right)+v_{i t} \\
& y_{i t}=\alpha+\left(x_{i t}-\bar{x}_{i}\right) \beta^{\text {within }}+\bar{x}_{i} \beta^{\text {between }}+v_{i t} .
\end{aligned}
$$

It can now be seen in equation (5) that each variable is allowed to influence $y$ through two orthogonal components: its 'within' dimension and its 'between' dimension. This formulation of the CRE model is sometimes called a 'hybrid' model because it allows for the simultaneous, direct and independent estimation of both $\beta^{\text {within }}$ and $\beta^{\text {between }} 6$

\footnotetext{
'Independence' means that the 'within' estimates can be obtained, even in the absence of the group means. This would not be the case in the CRE model, where the presence of group means is required to implicitly induce a within transformation of the untransformed variable. This independence motivates our preference for the hybrid model when applying BMA.
} 
Finally, even model (5) may be too restrictive, if slope heterogeneity not only exist across data dimensions but also across (groups of) countries:

$$
y_{i t}=\alpha+\left(x_{i t}-\bar{x}_{i}\right) \beta_{i}^{\text {within }}+\bar{x}_{i} \beta_{i}^{\text {between }}+v_{i t}
$$

where a subscript $i$ is now attached to the $\beta$ s. Assuming parameter homogeneity leads to the estimation of averages of group-specific estimators, where the weights are a function of the proportion of variance in each group. If slopes differ across groups, these averages will have little meaning. Splitting the overall sample in meaningful groups is a popular way to assess whether cross-country parameter homogeneity is appropriate.

\section{Bayesian Model Averaging}

There are a large number of potential determinants of the $\mathrm{CAB}$ and, thus, a large number of potential explanatory variables that could be included in a panel data regression model which has the CAB as the dependent variable. In such a case, conventional econometric methods, which typically involve the use of hypothesis tests to select explanatory variables and then running a final regression using the selected variables, can run into problems. First, such an approach ignores model uncertainty since it assumes the final regression is the one which generated the data. If we have $K$ potential explanatory variables, then there are $2^{K}$ possible restricted models which include some sub-set of the $K$ variables. Particularly if $K$ is large (as will be our case), treating one model as if it were 'true' and ignoring all the rest is problematic. Second, the fact that the selected model has been chosen using hypothesis testing procedures adds weight to the first criticism due to the pre-test problem. That is, if a single hypothesis test has a 5\% level of significance, using such a test sequentially for multiple tests requires adjustment of the p-values. With $2^{K}$ potential models and, thus, a huge number of possible tests, the pre-test problem can be serious in applications such as ours.

In light of these considerations, a growing number of economists have been using BMA in applications involving cross-country data sets with many potential explanatory variables. Early work in economics often involved cross-country growth regressions. Key references include Sala-i Martin (1997), Fernandez et al. (2001), Doppelhofer et al. (2004), Doppelhofer and Weeks (2009), Eicher et al. (2009), Ley and Steel (2009) and Moral-Benito (2012). But there has also been a huge increase of BMA applications in other fields of 
economics (see, among many others, Avramov (2002), Koop and Potter (2004), and Cuaresma and Slacik (2009)). Most of these applications involve cross-country data sets, but increasingly BMA is used with panel data, e.g. Moral-Benito (2012). Moral-Benito (2015) provides an excellent survey of BMA methods in economics.

The theoretical justification of BMA is based on the treatment of the models as random variables and use of the rules of probability. That is, if $M_{i}$ for $i=1, . ., m$ are models and we are uncertain which model generated the data, then the posterior model probability, $p\left(M_{i} \mid D a t a\right)$, summarizes this uncertainty. If $\theta$ is a feature of interest which is common to all models (e.g. the marginal effect of an explanatory variable on a dependent variable or a forecast), then the rules of probability imply:

$$
p(\theta \mid \text { Data })=\sum_{i=1}^{m} p\left(\theta \mid M_{i}, \text { Data }\right) p\left(M_{i} \mid \text { Data }\right) .
$$

In words, overall empirical results should be based on the posterior for the feature of interest, $p(\theta \mid$ Data), which can be obtained by averaging results from the posterior for each individual model, $p\left(\theta \mid M_{i}\right.$, Data $)$. The weights in the averaging process are the posterior model probabilities. In practice, it is common to use non-informative prior approximations to $p\left(\theta \mid M_{i}\right.$, Data $)$ and $p\left(M_{i} \mid\right.$ Data $)$, a practice we follow in this paper. We use the panel data estimators discussed in the preceding section for the former and weights based on the Bayesian information criterion (BIC) for the latter. BIC is an asymptotic approximation to the log of the marginal likelihood which, assuming equal prior weights is attached to each model, is proportional to the $\log$ of the posterior model probability. Thus, if $B I C_{i}$ is the BIC of $M_{i}$,

$$
p\left(M_{i} \mid \text { Data }\right) \approx \frac{\exp \left(-\frac{1}{2} B I C_{i}\right)}{\sum_{j=1}^{m} \exp \left(-\frac{1}{2} B I C_{j}\right)} .
$$

In summary, BMA requires four things: i) a set of models, ii) a method for estimating each individual model within this set, iii) a method for calculating the weight attached to each model when averaging, and iv) a computational method for navigating through the set of models. In line with our previous discussion on the merits and drawbacks of various panel data estimators, we implement our BMA approach by estimating the hybrid model, first assuming cross-country homogeneity and then considering slope heterogeneity between OECD and non-OECD countries. ${ }^{7}$ Our unrestricted models include (transformations of) all the potential

\footnotetext{
${ }^{7}$ Since this is a frequentist estimator, methods such as ours are sometimes referred to as Bayesian averaging of classical estimates (BACE). But, given that such estimates usually approximate Bayesian non-informative prior estimates, we will retain
} 
variables in $x_{i t}$ and we consider every possible restriction on these models. We use BIC-based weights to average over the models. In practice, exploring $2^{K}$ models is not feasible. Thus, following much of the previous literature, we use the Markov Chain Monte Carlo Model Composition $\left(\mathrm{MC}^{3}\right)$ algorithm of Madigan et al. (1995).

In addition to point estimates (i.e. posterior means), we also present a Bayesian t-statistic which is the posterior mean divided by the posterior standard deviation. It is worth emphasising that, formally, this is not part of a test of significance. However, informally, a Bayesian t-statistic which says that a posterior mean is more that two posterior standard deviations from zero indicates that the vast majority of posterior probability lies in the non-zero region and, thus, indicates the associated variable has important explanatory power. Another useful measure of the importance of an explanatory variable is the posterior inclusion probability (PIP). This is calculated as the proportion of models drawn by the $\mathrm{MC}^{3}$ algorithm which contain the corresponding explanatory variable. The PIP for a variable can be interpreted as the probability attached to models that include the variable. It is a useful diagnostic for deciding whether an individual explanatory variable has an important role. In this paper, a variable is deemed to be a relevant explanatory factor when its PIP exceeds the threshold value of 0.75 .

We apply our BMA approach to the External Balance Assessment developed by the IMF.

\section{BMA approach to the EBA exercise}

\subsection{Description of the EBA}

The purpose of the External Balance Assessment (EBA) developed by the IMF is to identify the key determinants of the $\mathrm{CAB}$ (or the real exchange rate) and then use these results to make normative evaluations. Our paper is concerned with the first stage of the EBA exercise.

The econometric model of the EBA is based on the following reduced-form equation, which combines the investment-saving relation with the balance-of-payments relation:

$$
C A B=C A B\left(X_{I}, X_{S}, X_{C A}, X_{C F}, Z, Z^{W O}, \Delta R\right)
$$

the BMA terminology. 
where the $X$ s are factors related to $I$ nvestment, $S$ aving/consumption, $C A$ : export/imports, $C$ apital $F$ lows; $Z \mathrm{~s}$ is either $W O$ rld output gap or short-term interest rate; $\Delta R$ is the change in foreign exchange Reserves. The variables included in the model have been chosen by the IMF on the basis of ex-ante theoretical priors and ex-post tests of statistical significance. These variables are described in Table 1. They can be classified in four main categories: structural, cyclical, policy, and initial conditions. Our BMA considers all these variables as potential determinants of the CAB. Data directly come from the IMF EBA website, ${ }^{8}$ except the credit to GDP ratio which is taken from the World Bank. Table 2 lists the countries in the sample. There are 22 rich OECD countries and 27 other countries. All these countries appear to experience large yearly fluctuations in their CABs. The period covered by the sample is 1986-2013.

Table 3 provides a decomposition of the variation of these variables intheir between and within components. Values of CABs are equally driven by average differences across countries and changes within countries. In line with their classification, structural variables tend to be characterised by high 'between' variation and low 'within' variation whereas the opposite tends to hold true for cyclical and policy variables. From an econometric perspective, low variation means difficult identification. It is therefore worthwhile to consider the estimates obtained using both sources of variation.

[Table 1 about here.]

[Table 2 about here.]

[Table 3 about here.]

\subsection{BMA results}

Results are presented in Tables 4-5. Using the full sample, we first assume slope homogeneity across country groups and, in a second stage, we allow for slope heterogeneity between OECD and non-OECD countries. At the bottom of each table, in addition to the average number of variables in each model, we report the sum of the posterior model probabilities (PMPs) of the top two models. These probabilities correspond to the proportion of draws taken from each model by the $\mathrm{MC}^{3}$ algorithm.

[Table 4 about here.]

[Table 5 about here.]

\footnotetext{
${ }^{8}$ https://www.imf.org/external/np/res/eba/data.htm
} 
Table 4 shows that several variables included in the IMF-EBA model are not 'BMA relevant', with a PIP close to zero. The set of relevant variables varies across data dimensions. Within estimates suggest that changes in $\mathrm{CABs}$ are associated with changes in cyclical factors and policies while between estimates indicate that differences in average CABs across countries tend to be related to structural factors. This split agrees with economic intuition: transitory factors are associated with short-run movements in CABs whereas slow-changing factors, such as demographic variables, are associated with durable differences in CABs across countries. Variables deemed to be relevant have the expected sign (see Table 1).

Table 6 shows what would have happened if we had not decomposed the data into within and between dimensions by combining BMA with a pooled estimator. A comparison of these results with those given in Table 4 indicates that these estimates would have reflected the within estimates. In other words, the weight given to the within estimator in the computation of the OLS estimator is extremely large in the context of our empirical application. This implies that the pooled model, despite the absence of country fixed effects, estimates in practice determinants of short-run changes in CABs. ${ }^{9}$

\section{[Table 6 about here.]}

The sum of the PMPs of the top two models is relatively low (0.11), highlighting that there is considerable uncertainty about the right model. It is possible that this poor performance is the outcome of slope heterogeneity across country groups. In Table 5, we thus allow for slope heterogeneity across country groups by including interactions between every potential determinant of CABs and an OECD dummy variable. Relative to the results of Table 4, The sum of the PMPs of the top two models is substantially higher (from 0.11 to 0.20 ), indicating a reduction in model uncertainty, and we also observe a larger number of relevant variables, e.g. fiscal balance or capital controls. OECD and non-OECD countries appear to have many determinants in common. Nevertheless, slope homogeneity is occasionally rejected. For example, changes in the fiscal balance has little effect on CABs in non-OECD countries but a large impact on the CABs of OECD countries. Looking across data dimensions, there is again a 'natural' split between cyclical and policy factors having more of a short-run effect and structural factors being associated with variations in average $\mathrm{CABs}$ across countries. In light of the events surrounding the global financial crisis as well as

\footnotetext{
${ }^{9}$ The sum of the PMPs of the top two models is high. This is certainly because these models do a good job at predicting short-run changes in CABs (we obtain similar results when estimating a model solely based on group deviations). This does not imply that they would perform as well to explain overall changes in CABs.
} 
the Euro crisis, it is worth highlighting the negative impact on CABs of high growth expectations, a positive output gap, a rising fiscal deficit, or excessive credit.

\subsection{Discussion}

Our results provide a contrasted perspective on the 'effectiveness' of the IMF-EBA model. With the use of a pooled estimator (Table 6), we would conclude that a large number of variables put forward by the academic literature and included in the IMF-EBA model are not relevant when alternative models are considered. Once we allow for heterogenous responses across time horizons (Table 4) and country groups (Table 5), this conclusion appears to be too harsh. The high model uncertainty highlighted by BMA is often the outcome of assuming that the effects of a variable are the same across time or across space.

The interpretation of the 'between' estimates is difficult because we cannot rule out that unobserved country heterogeneity generates an omitted variable bias. Two responses can be given to this issue.

First, a distinction ought to be made in the use of a model for 'explaining' and for 'predicting'. Even in absence of causal interpretation, the 'between' estimates remain useful to predict CABs values since they directly capture the effects of observed variables, and indirectly, the effects of some omitted variables. They complement the 'within' estimates, which have a more causal interpretation, and can therefore be used to explain the likely effects of factors such as government policies.

Second, the robustness of the 'between' estimates to the inclusion of country fixed effects can be assessed to evaluate their causal nature. In the context of the OLS estimator, this is clearly impossible since there would be perfect multicollinearity between the fixed effects and the group means. However, this is possible, at least to a certain extent, using other modelling techniques such as ridge regression.

In the next two sections, we provide empirical applications to illustrate these two responses.

\section{Prediction and normative evaluation of current account gaps}

In this section, we explore the usefulness of our BMA exercise for the predictions and evaluations of current account gaps. In Table 7, we estimate two models. The first model is a pooled model in which all variables are included and homogeneity across time and space is assumed. ${ }^{10}$ The second model is our 'best' hybrid

\footnotetext{
${ }^{10}$ We follow the IMF-EBA approach by using the Prais-Winsten transformation to deal with first-order autocorrelation.
} 
model in the sense that we include all variables which are considered to be relevant in Table 5. Table 7 shows that the estimates between the two models tend to have the same sign but are often of a very different order of magnitude. Interestingly, the estimates of the hybrid model tends to be close to those obtained in Table 5. Figure 1 depicts the median absolute differences between observed and predicted values, by year and country groups. Our hybrid model appears to perform better, in the sense that for most years, the deviations are smaller than those of the pooled model.

\section{[Table 7 about here.]}

[Figure 1 about here.]

The IMF uses the predicted values generated by a pooled model to guide its normative evaluation of CABs. A pooled model without country fixed effects or lagged dependent variable is estimated because the IMF does not want to inflate the predictive power of their model by including proxies for unobservables. The gaps between actual and predicted values are decomposed in an unexplained gap and a policy gap. The latter, driven by variables which are expected to be under policy control in the short run (fiscal balances, capital controls, social spending, reserve accumulation, and financial policies), corresponds to the estimated coefficients times the difference between observed and desirable values of the policy variables. The two stages of this approach can be refined by using a hybrid model rather than a pooled model while keeping the spirit of the approach intact. The better fit of the hybrid model means smaller residuals to explain. This implies that our knowledge of the determinants of CABs, or their surrogates if we believe that the 'between' estimates are tainted by an omitted variable bias, is better than what the predictions of the pooled model would suggest. In addition, focusing on the 'within' estimates of policy variables allows for more robust normative evaluations. These coefficients tend to capture short-run effects and can be given a more causal interpretation since they are robust to country heterogeneity. Finally, the hybrid model obeys the self-imposed modelling rules of the IMF which justify their use of a pooled model: no country fixed effects or lagged dependent variable are included. Nevertheless, the coefficients on group deviations are still those that we would obtain in a fixed effects model and, as discussed in Section 2, the 'between' estimates provide some indications on long-run effects, as long as one is willing to assume that group means are uncorrelated with unobserved country heterogeneity. 
Our way of dealing with slope heterogeneity follows the common practice of economists and practitioners to decompose the world in OECD and non-OECD countries as these two groups are often expected to have different behaviours. ${ }^{11}$ We could have gone one step further and allow for full slope heterogeneity. ${ }^{12}$ However, that would have created a tension between model flexibility and model operativeness. Assuming that one wants to use the estimated model to do a normative evaluation similar in spirit to the one carried out by the IMF in its EBA exercise, some cross-country constraints must be imposed to formulate 'general' policy recommendations. This preliminary normative analysis can then be adjusted using additional information and the judgement of country experts. This is the iterative approach adopted by the IMF to obtain a full assessment of external balances.

\section{Dealing with unobserved country heterogeneity in a cross-sectional \\ setting}

Our 'between' estimates may not truly capture the long-run responses of CABs as we cannot discount the possibility of an omitted variable bias due to unobserved country heterogeneity. Hence, we wish to investigate whether our cross-sectional results are robust to the presence of country-specific fixed effects. This can be done through adding to the between regression in (2) a fixed effect for every country (i.e. adding a dummy variable for each country). This sounds impossible to do since such a regression would have more explanatory variables $(N+K)$ than observations $(N)$. Nevertheless, there is an increasing recognition that statistical methods exist to handle such cases. ${ }^{13}$

We now do BMA over a set of cross-sectional regressions where the set of explanatory variables contains all those in Table 1 plus $N$ fixed effects. Our BMA methods have to be slightly modified since the OLS estimator and BIC cannot be applied when the number of regression coefficients is greater than the sample size (nor can the g-prior, a common choice in BMA literature, be employed). To explain the necessary modifications, note that BMA requires two things: i) a method for estimating regression coefficients in

\footnotetext{
${ }^{11}$ See for example the debate on global imbalances and the 'savings glut' initiated by Bernanke. The current account deficits of developed countries, notably the USA, are seen as the manifestation of the current account surpluses of emerging countries. See also Chinn and Prasad (2003) and Chinn and Ito (2007) for classical papers in the literature investigating current account determinants separately for industrial and developing countries.

${ }^{12}$ See Moral-Benito and Viani (2017) for such an application to the Spanish case.

${ }^{13}$ See for example this blog post aptly named 'Fixed effects without panel data': https: / / fxdiebold.blogspot. co. uk/2016/06/fixed-effects-without-panel-data.html.
} 
each model; ii) weights for averaging across models. Consider first the estimation with a large number of explanatory variables question. In the machine learning literature, there are several methods for dealing with this issue (e.g. the Least absolute shrinkage and selection operator or LASSO). Many of these can be given a Bayesian interpretation (Korobilis, 2013). In this paper, we apply the commonly used ridge regression methods (see Hoerl and Kennard (1970)). The Bayesian interpretation of ridge regression methods is that they amount to the use of a shrinkage prior. If $\beta$ denotes all the regression coefficients (including the coefficients on the country-specific dummy variables) and $\sigma^{2}$ is the error variance, then ridge regression amounts to using a $N\left(0, \tau \times \sigma^{2} I\right)$ prior where $\tau$ controls the strength of shrinkage (in this paper we set $\tau=10$ which is a relatively non-informative choice). This prior is natural conjugate and standard textbook results for Bayesian analysis of the regression model (e.g., chapter 3 in Koop (2003)), and can be used to produce an estimate of any coefficient (i.e. its posterior mean) and the uncertainty associated with the estimate (i.e. its posterior variance). Crucially, both of these can be obtained even when the number of explanatory variables is greater than the number of observations. ${ }^{14}$ In addition, the marginal likelihood exists in this case. The marginal likelihood is the standard Bayesian method of model comparison and, asymptotically, its log converges to the BIC. Accordingly, it can be used to produce weights for the model averaging.

[Table 8 about here.]

Table 8 presents the results of our BMA-ridge regression estimation. Given that ridge regression involves standardisation of all variables before estimation, the estimated coefficients are not comparable to those in previous Tables. For this reason, we focus on PIP and sign of the coefficients. It can be seen that most PIPs are well below our threshold of relevance. This is certainly because we are asking a lot from the data: we have 49 observations, 55 control variables, and 49 fixed effects. Nevertheless, the variables with high PIP (above 0.50 here) tend be those with high PIP (above 0.75) in Table 5 and both tend to share similar signs , e.g. political risk; fiscal balance; international indebtedness. Other variables, like 'public health spending' now appears relevant to explain average differences in CABs across countries. Overall,

\footnotetext{
${ }^{14}$ In the Bayesian literature, identification is defined in terms of the likelihood function. If every value of a parameter produces a distinct value for the likelihood function, then the parameter is identified. If multiple values for a parameter lead to identical values for the likelihood function then the parameter is not identified. Thus, in our case (or any regression with $\mathrm{K}_{i} \mathrm{~N}$ where $\mathrm{K}$ is the number of parameters and $\mathrm{N}$ is the number of observations), the regression coefficients are not identified. However, this lack of identification does not preclude Bayesian estimation of regressions with $\mathrm{K}_{\boldsymbol{\iota}} \mathrm{N}$ due to the prior. Provided the prior is proper (integrates to one), the posterior will also be proper and valid Bayesian inference is possible.
} 
these results suggest that some of the 'between' estimates in Table 4 may reflect a causal relationship, albeit with caveats.

\section{Conclusion}

Looking at the specific examination of the determinants of current account balances, this paper highlights three features which are likely to be shared by many panel data applications: high model uncertainty, presence of slope heterogeneity, and potential divergence in short-run and long-run effects. The methodologies deployed in this paper provide a response to these various issues. Their use ought to allow for more flexible modelling and, by extension, a better understanding of the economic factors driving the outcome of interest. 


\section{References}

Aizenman, Joshua and Jinjarak, Yothin (2009) 'Current account patterns and national real estate markets', Journal of Urban Economics, Vol. 66, pp. 75-89.

Avramov, Doron (2002) 'Stock return predictability and model uncertainty', Journal of Financial Economics, Vol. 64, pp. 423-258.

Baltagi, Badi H. and Griffin, James M. (1984) 'Short and long run effects in pooled models', International Economic Review, Vol. 25, pp. 631-645.

Bell, Andrew and Jones, Kelvyn (2015) 'Explaining fixed effects: random effects modeling of time-series cross-sectional and panel data', Political Science Research and Methods, Vol. 3, pp. 133-153.

Bernanke, Ben (2013) 'The global saving glut and the current account deficit',Technical report, Sandridge Lecture, Virginia association of economics, Richmond, Virginia, Federal Reserve Board.

Ca Zorzi, Michele, Chudik, Alexander, and Dieppe, Alistair (2012) 'Thousands of models, one story: current account imbalances in the global economy', Journal of International Money and Finance, Vol. 31, pp. 1319-1338.

Caballero, Ricardo J., Farhi, Emmanuel, and Gourinchas, Pierre-Olivier (2008) 'An equilibrium model of global imbalances and low interest rates’, American Economic Review, Vol. 98, pp. 358-93.

Chinn, Menzie D., Eichengreen, Barry, and Ito, Hiro (2014) 'A forensic analysis of global imbalances', Oxford Economic Papers, Vol. 66, pp. 465-490.

Chinn, Menzie D. and Ito, Hiro (2007) 'Current account balances, financial development and institutions: assaying the world 'saving glut', Journal of International Money and Finance, Vol. 26, pp. 546-569.

Chinn, Menzie D. and Prasad, Eswar S. (2003) 'Medium-term determinants of current accounts in industrial and developing countries: an empirical exploration', Journal of International Economics, Vol. 59, pp. 47-76.

Ciocyte, Ona and Rojas-Romagosa, Hugo (2015) 'Literature survey on the theoretical explanations and empirical determinants of current account balances’, CPB Background Paper.

Clark, Tom S. and Linzer, Drew A. (2015) 'Should I use fixed or random effects?', Political Science Research and Methods, Vol. 3, pp. 399-408.

Cuaresma, Jesús Crespo and Slacik, Tomas (2009) 'On the determinants of currency crises: the role of model uncertainty', Journal of Macroeconomics, Vol. 31, pp. 621-632.

Doppelhofer, Gernot, Miller, Ronald I., and Sala-i Martin, Xavier (2004) 'Determinants of long-term growth: a Bayesian Averaging of Classical Estimates (BACE) approach', American Economic Review, Vol. 94, pp. 813-835.

Doppelhofer, Gernot and Weeks, Melvyn (2009) 'Jointness of growth determinants', Journal of Applied Econometrics, Vol. 2, pp. 209-244.

Egger, Peter and Pfaffermayr, Michael (2002) 'Long and Short Run Effects in Static Panel Models', mimeo. (2005) 'Estimating Long and Short Run Effects in Static Panel Models', Econometric Reviews, Vol. 23, pp. 199-214. 
Eicher, Theo S., Papageorgiou, Chris, and Raftery, Adrian E. (2009) 'Default priors and predictive performance in Bayesian model averaging, with application to growth determinants', Journal of Applied Econometrics, Vol. 26, pp. 30-55.

Fernandez, Carmen, Ley, Eduardo, and Steel, Mark FJ. (2001) 'Model uncertainty in cross-country growth regressions', Journal of Applied Econometrics, Vol. 16, pp. 563-576.

Fogli, Alessandra and Perri, Fabrizio (2006) 'The great moderation and the U.S. external imbalance', Monetary and Economic Studies, Vol. 24, pp. 209-225.

Fratzscher, Marcel and Straub, Roland (2009) 'Asset prices and current account fluctuations in G-7 economies', IMF Staff Papers, Vol. 56, pp. 633-654.

Gourinchas, Pierre-Olivier and Rey, Helene (2014) 'External adjustment, global imbalances, valuation effects', in Gita Gopinath, Elhanan Helpman, and Kenneth Rogoff eds. Handbook of International Economics: Elsevier, Chap. 10, pp. 585-645.

Greene, William (2008) Econometric Analysis: New Jersey: Peason Prentice Hall, 6th edition.

Hoerl, Arthur E. and Kennard, Robert W. (1970) 'Ridge regression: biased estimation for nonorthogonal problems', Technometrics, Vol. 12, pp. 55-67.

IMF (2013) 'External balance assessment (EBA) methodology: technical background',Technical report, International Monetary Fund.

Koop, Gary (2003) Bayesian Econometrics: Chichester: Wiley.

Koop, Gary and Potter, Simon (2004) 'Forecasting in dynamic factor models using Bayesian model averaging', The Econometrics Journal, Vol. 7, pp. 550-565.

Korobilis, Dimitris (2013) 'Hierarchical shrinkage priors for dynamic regressions with many predictors', International Journal of Forecasting, Vol. 29, pp. 43-59.

Lane, Philip R. and Milesi-Ferretti, Gian Maria (2012) 'External adjustment and the global crisis', Journal of International Economics, Vol. 88, pp. 252-265.

Ley, Eduardo and Steel, Mark FJ. (2009) 'On the effect of prior assumptions in Bayesian model averaging with applications to growth regression', Journal of Applied Econometrics, Vol. 24, pp. 651-674.

Madigan, David, York, Jeremy, and Allard, Denis (1995) 'Bayesian graphical models for discrete data', International Statistical Review, Vol. 63, pp. 215-232.

Sala-i Martin, Xavier (1997) 'I Just Ran Two Million Regressions', American Economic Review, Vol. 87, pp. 178-183.

Moral-Benito, Enrique (2012) 'Determinants of economic growth: a Bayesian panel data approach', The Review of Economics and Statistics, Vol. 94, pp. 566-579.

(2015) 'Model averaging in economics: an overview', Journal of Economic Surveys, Vol. 29, pp. $46-75$.

Moral-Benito, Enrique and Roehn, Oliver (2016) 'The impact of financial regulation on current account balances', European Economic Review, Vol. 81, pp. 148-166.

Moral-Benito, Enrique and Viani, Francesca (2017) 'An anatomy of the spanish current account adjustment: the role of permanent and transitory factors', Working Papers 1737, Banco de Espana; Working Papers. 
Obstfeld, Maurice and Rogoff, Kenneth (1995) 'The intertemporal approach to the current account', in Gene M. Grossman and Kenneth Rogoff eds. Handbook of International Economics, Vol. 3 of Handbook of International Economics: Elsevier, Chap. 34, pp. 1731-1799.

Pesaran, Hashem M. and Smith, Ron (1995) 'Estimating long-run relationships from dynamic heterogeneous panels', Journal of econometrics, Vol. 68, pp. 79-113.

Pirotte, Alain (1999) 'Convergence of the static estimation toward the long run effects of dynamic panel data models’, Economics Letters, Vol. 63, pp. 151-158.

(2003) 'Convergence of the static estimation toward the long run effects of dynamic panel data models: a labour demand illustration’, Applied Economics Letters, Vol. 10, pp. 843-847.

Pirotte, Alain and Mur, Jesús (2017) 'Neglected Dynamics and Spatial Dependence on Panel Data: Consequences for Convergence of the Usual Static Model Estimators', Spatial Economic Analysis, Vol. 12, pp. 202-229.

Wolf, Martin (2014) The Shifts and the Shocks: London: Penguin Books. 


\section{Structural}

Dependency Ratio \#

Aging speed \# $\Omega$

Population Growth \#

L.Output per worker, relative to top 3 economies

Safer Institutional/Political Environment (index) \#

\section{Cyclical}

GDP growth, forecast in 5 years \#

Output Gap \#

L.demeaned VIX $\Omega$

Oil and Natural Gas Trade Balance * resource temporariness \#

Commodity ToTgap $\Omega *$ Trade Opennes

Changes in reserves, instrumented \#

\section{Policy}

Cyclically adjusted Fiscal Balance, instrumented \#

L.Public Health Spending/GDP \#

Private Credit/GDP \#

Capital controls $\Omega$

\section{Initial conditions}

Lagged net foreign assets to GDP ratio

Own currency share in world reserves

Financial centre status
Ratio of population aged over 65 divided by population between 30 and 64 years old. Also interacted with Aging Speed

Projected change in the dependency ratio ratio 20 years out, relative to current level. Also interacted with Dependency Ratio

Growth rate of the population

Ratio of PPP GDP to working age population relative to average of Germany, Japan, an U.S., demeaned. Also interacted with K controls (see below)

Average of 5 indicators from the International Country Risk Guide: socioeconomic conditions; investment profile; corruption; religious tensions; and democratic accountability. Higher values signify less risk

Projections of the rate of real GDP growth 5 years ahead. Measured relative to the weighted world GDP averaged output gap

Estimated gap between current output and trend output

VXO is an index of implied U.S. stock market volatility; it is interacted with K controls (see below). The latter interaction term is also interacted with the respective country's share of its own currency share in world reserves (see below)

Positive net exports of oil and natural gas, as percentage of GDP, multiplied by a measure of resource exhaustion

Deviations from trend of a trade-weighted commodity terms of trade index. Also interacted with trade openness, measured as the ratio of exports and imports in goods and services in GDP

Change in central bank foreign exchange reserves during the year scaled by nominal GDP, both in U.S. dollars, interacted with capital controls. Instrumented.

Fiscal balance adjusted for the business cycle, instrumented

Proxy for social protection policy

Private credit to GDP ratio

Index on overall capital controls on the private sector (no controls to full controls).

Previous year's value of the external net wealth to GDP ratio. Also interacted with a dummy variable taking the value of one if the net foreign asset position is less than $-60 \%$ of GDP $\Omega$

Share of the country's own currency in total stock of world reserves

Dummy variable that equals 1 for The Netherlands and for Switzerland throughout the estimation period, and for Belgium also, but only through 2004

$\begin{array}{cc}-;+ & \downarrow \text { saving } \\ +;+ & \uparrow \text { saving } \\ - & \downarrow \text { saving }\end{array}$

to low productivity countries

$\uparrow$ investment and $\downarrow$ saving

\section{$\uparrow$ investment $/ \downarrow$ saving}

$\uparrow$ investment and $\downarrow$ saving

$+;-;-\quad$ Capital outflows; capital inflows due to flight to safety

$\uparrow$ saving

Better terms of trade

Reserve accumulation

$\uparrow$ saving if Ricardian equivalence does not hold

Precautionary saving $\downarrow$

Credit boom: $\downarrow$ saving / $\uparrow$ investment

Exorbitant privilege

Ad-hoc. 
Table 2: Countries in the sample

\begin{tabular}{cccccccc}
\hline ISO code & OECD & Mean CA/Y & Std. Dev. & ISO code & OECD & Mean CA/Y & Std. Dev. \\
\hline ARG & 0 & -0.003 & 0.028 & ITA & 1 & -0.006 & 0.019 \\
AUS & 1 & -0.043 & 0.012 & JPN & 1 & 0.027 & 0.010 \\
AUT & 1 & 0.008 & 0.020 & KOR & 0 & 0.018 & 0.032 \\
BEL & 1 & 0.033 & 0.029 & LKA & 0 & -0.051 & 0.027 \\
BRA & 0 & -0.014 & 0.020 & MAR & 0 & -0.014 & 0.043 \\
CAN & 1 & -0.008 & 0.023 & MEX & 0 & -0.021 & 0.016 \\
CHE & 1 & 0.080 & 0.037 & MYS & 0 & 0.056 & 0.085 \\
CHL & 0 & -0.011 & 0.028 & NLD & 1 & 0.050 & 0.025 \\
CHN & 0 & 0.041 & 0.027 & NOR & 1 & 0.058 & 0.070 \\
COL & 0 & -0.020 & 0.021 & NZL & 1 & -0.039 & 0.020 \\
CRI & 0 & -0.046 & 0.016 & PAK & 0 & -0.018 & 0.032 \\
CZE & 0 & -0.034 & 0.018 & PER & 0 & -0.031 & 0.031 \\
DEU & 1 & 0.028 & 0.031 & PHL & 0 & -0.003 & 0.036 \\
DNK & 1 & 0.031 & 0.018 & POL & 0 & -0.038 & 0.021 \\
EGY & 0 & 0.001 & 0.029 & PRT & 1 & -0.047 & 0.047 \\
ESP & 1 & -0.031 & 0.031 & RUS & 0 & 0.068 & 0.047 \\
FIN & 1 & 0.016 & 0.042 & SWE & 1 & 0.036 & 0.036 \\
FRA & 1 & 0.000 & 0.010 & THA & 0 & 0.008 & 0.060 \\
GBR & 1 & -0.021 & 0.012 & TUN & 0 & -0.037 & 0.022 \\
GRC & 1 & -0.055 & 0.042 & TUR & 0 & -0.025 & 0.030 \\
GTM & 0 & -0.043 & 0.020 & URY & 0 & -0.017 & 0.019 \\
HUN & 0 & -0.048 & 0.042 & USA & 1 & -0.029 & 0.015 \\
IDN & 0 & 0.012 & 0.024 & ZAF & 0 & -0.009 & 0.029 \\
IND & 0 & -0.014 & 0.015 & & & & \\
IRL & 1 & 0.001 & 0.030 & OECD & 1 & -0.011 & 0.044 \\
ISR & 1 & 0.006 & 0.027 & Non-OECD & 0 & 0.003 & 0.047 \\
& & & & & & & \\
\hline
\end{tabular}


Table 3: Decomposition of variables in between and within components

\begin{tabular}{|c|c|c|c|c|c|c|c|c|c|c|c|}
\hline Variable & Variation & Mean & Std. Dev. & Min & Max & Variable & Variation & Mean & Std. Dev. & Min & Max \\
\hline Current account balance & $\begin{array}{c}\text { overall } \\
\text { between } \\
\text { within }\end{array}$ & -0.005 & $\begin{array}{l}0.046 \\
0.034 \\
0.032\end{array}$ & $\begin{array}{l}-0.145 \\
-0.055 \\
-0.158\end{array}$ & $\begin{array}{l}0.180 \\
0.080 \\
0.115\end{array}$ & Commodity ToTgap & $\begin{array}{l}\text { overall } \\
\text { between } \\
\text { within }\end{array}$ & -0.001 & $\begin{array}{l}0.067 \\
0.008 \\
0.067\end{array}$ & $\begin{array}{l}-0.334 \\
-0.030 \\
-0.349\end{array}$ & $\begin{array}{l}0.412 \\
0.025 \\
0.387\end{array}$ \\
\hline Dependency Ratio \# & $\begin{array}{c}\text { overall } \\
\text { between } \\
\text { within }\end{array}$ & -0.040 & $\begin{array}{l}0.094 \\
0.092 \\
0.020\end{array}$ & $\begin{array}{l}-0.188 \\
-0.179 \\
-0.158\end{array}$ & $\begin{array}{l}0.235 \\
0.105 \\
0.125\end{array}$ & Trade Openness & $\begin{array}{l}\text { overall } \\
\text { between } \\
\text { within }\end{array}$ & 0.324 & $\begin{array}{l}0.180 \\
0.168 \\
0.069\end{array}$ & $\begin{array}{c}0.041 \\
0.105 \\
-0.023\end{array}$ & $\begin{array}{l}1.101 \\
0.871 \\
0.554\end{array}$ \\
\hline Aging Speed \# & $\begin{array}{c}\text { overall } \\
\text { between } \\
\text { within }\end{array}$ & -0.039 & $\begin{array}{l}0.057 \\
0.050 \\
0.027\end{array}$ & $\begin{array}{l}-0.184 \\
-0.147 \\
-0.158\end{array}$ & $\begin{array}{l}0.185 \\
0.136 \\
0.070\end{array}$ & Commodity ToTgap*Trade Openness & $\begin{array}{c}\text { overall } \\
\text { between } \\
\text { within }\end{array}$ & -0.001 & $\begin{array}{l}0.019 \\
0.003 \\
0.019\end{array}$ & $\begin{array}{l}-0.115 \\
-0.010 \\
-0.119\end{array}$ & $\begin{array}{l}0.118 \\
0.008 \\
0.110\end{array}$ \\
\hline rel. Dependency Ratio*Aging Speed & $\begin{array}{c}\text { overall } \\
\text { between } \\
\text { within }\end{array}$ & -0.026 & $\begin{array}{l}0.051 \\
0.043 \\
0.026\end{array}$ & $\begin{array}{l}-0.178 \\
-0.113 \\
-0.153\end{array}$ & $\begin{array}{l}0.213 \\
0.156 \\
0.077\end{array}$ & Oil and Natural Gas Trade Balance * resource temporariness \# & $\begin{array}{c}\text { overall } \\
\text { between } \\
\text { within }\end{array}$ & 0.003 & $\begin{array}{l}0.020 \\
0.019 \\
0.008\end{array}$ & $\begin{array}{l}-0.005 \\
-0.004 \\
-0.062\end{array}$ & $\begin{array}{l}0.215 \\
0.118 \\
0.099\end{array}$ \\
\hline rel. Aging Speed $*$ Dependency Ratio & $\begin{array}{c}\text { overall } \\
\text { between } \\
\text { within }\end{array}$ & -0.013 & $\begin{array}{l}0.067 \\
0.056 \\
0.036\end{array}$ & $\begin{array}{l}-0.247 \\
-0.168 \\
-0.351\end{array}$ & $\begin{array}{l}0.257 \\
0.095 \\
0.150\end{array}$ & Cyclically adjusted Fiscal Balance, instrumented \# & $\begin{array}{c}\text { overall } \\
\text { between } \\
\text { within }\end{array}$ & 0.005 & $\begin{array}{l}0.023 \\
0.021 \\
0.011\end{array}$ & $\begin{array}{l}-0.080 \\
-0.042 \\
-0.038\end{array}$ & $\begin{array}{l}0.070 \\
0.055 \\
0.042\end{array}$ \\
\hline Population Growth \# & $\begin{array}{c}\text { overall } \\
\text { between } \\
\text { within }\end{array}$ & 0.002 & $\begin{array}{l}0.007 \\
0.007 \\
0.003\end{array}$ & $\begin{array}{l}-0.012 \\
-0.009 \\
-0.009\end{array}$ & $\begin{array}{l}0.022 \\
0.017 \\
0.012\end{array}$ & L.Public Health Spending/GDP \# & $\begin{array}{c}\text { overall } \\
\text { between } \\
\text { within }\end{array}$ & -0.012 & $\begin{array}{l}0.023 \\
0.022 \\
0.006\end{array}$ & $\begin{array}{l}-0.057 \\
-0.051 \\
-0.042\end{array}$ & $\begin{array}{l}0.036 \\
0.024 \\
0.014\end{array}$ \\
\hline L.Output per worker, relative to top 3 economies & $\begin{array}{c}\text { overall } \\
\text { between } \\
\text { within }\end{array}$ & 0.012 & $\begin{array}{l}0.367 \\
0.369 \\
0.046\end{array}$ & $\begin{array}{l}-0.526 \\
-0.510 \\
-0.235\end{array}$ & $\begin{array}{l}1.013 \\
0.933 \\
0.198\end{array}$ & Private Credit/GDP \# & $\begin{array}{l}\text { overall } \\
\text { between } \\
\text { within }\end{array}$ & -0.486 & $\begin{array}{l}0.483 \\
0.434 \\
0.198\end{array}$ & $\begin{array}{l}-1.298 \\
-1.061 \\
-1.478\end{array}$ & $\begin{array}{l}0.988 \\
0.704 \\
0.508\end{array}$ \\
\hline L.Relative output per worker*K openness & $\begin{array}{c}\text { overall } \\
\text { between } \\
\text { within }\end{array}$ & 0.065 & $\begin{array}{l}0.300 \\
0.297 \\
0.055\end{array}$ & $\begin{array}{l}-0.411 \\
-0.372 \\
-0.229\end{array}$ & $\begin{array}{l}1.013 \\
0.857 \\
0.259\end{array}$ & $\mathrm{~K}$ controls & $\begin{array}{c}\text { overall } \\
\text { between } \\
\text { within }\end{array}$ & 0.231 & $\begin{array}{l}0.250 \\
0.216 \\
0.138\end{array}$ & $\begin{array}{c}0.000 \\
0.000 \\
-0.207\end{array}$ & $\begin{array}{l}0.875 \\
0.757 \\
0.736\end{array}$ \\
\hline Safer Institutional/Political Environment (index) \# & $\begin{array}{c}\text { overall } \\
\text { between } \\
\text { within }\end{array}$ & -0.063 & $\begin{array}{l}0.145 \\
0.137 \\
0.056\end{array}$ & $\begin{array}{l}-0.553 \\
-0.414 \\
-0.257\end{array}$ & $\begin{array}{l}0.195 \\
0.130 \\
0.123\end{array}$ & L. NFA/Y & $\begin{array}{l}\text { overall } \\
\text { between } \\
\text { within }\end{array}$ & -0.221 & $\begin{array}{l}0.352 \\
0.310 \\
0.169\end{array}$ & $\begin{array}{l}-1.447 \\
-0.963 \\
-1.391\end{array}$ & $\begin{array}{l}1.383 \\
1.012 \\
0.265\end{array}$ \\
\hline GDP growth, forecast in 5 years \# & $\begin{array}{c}\text { overall } \\
\text { between } \\
\text { within }\end{array}$ & 0.006 & $\begin{array}{l}0.016 \\
0.015 \\
0.008\end{array}$ & $\begin{array}{l}-0.026 \\
-0.014 \\
-0.036\end{array}$ & $\begin{array}{l}0.060 \\
0.048 \\
0.037\end{array}$ & L. NFA/Y*(dummy if NFA/Y ; -60\%) & $\begin{array}{c}\text { overall } \\
\text { between } \\
\text { within }\end{array}$ & -0.024 & $\begin{array}{l}0.094 \\
0.068 \\
0.069\end{array}$ & $\begin{array}{l}-0.847 \\
-0.363 \\
-0.832\end{array}$ & $\begin{array}{l}0.000 \\
0.000 \\
0.193\end{array}$ \\
\hline Output Gap \# & $\begin{array}{c}\text { overall } \\
\text { between } \\
\text { within }\end{array}$ & 0.000 & $\begin{array}{l}0.027 \\
0.006 \\
0.026\end{array}$ & $\begin{array}{l}-0.143 \\
-0.013 \\
-0.134\end{array}$ & $\begin{array}{l}0.120 \\
0.022 \\
0.110\end{array}$ & Dummy if NFA/Y $i-60 \%$ & $\begin{array}{c}\text { overall } \\
\text { between } \\
\text { within }\end{array}$ & 0.099 & $\begin{array}{l}0.299 \\
0.222 \\
0.211\end{array}$ & $\begin{array}{c}0.000 \\
0.000 \\
-0.781\end{array}$ & $\begin{array}{l}1.000 \\
1.000 \\
1.063\end{array}$ \\
\hline L.demeaned VIX & $\begin{array}{c}\text { overall } \\
\text { between } \\
\text { within }\end{array}$ & -0.003 & $\begin{array}{l}0.065 \\
0.006 \\
0.065\end{array}$ & $\begin{array}{l}-0.093 \\
-0.013 \\
-0.110\end{array}$ & $\begin{array}{l}0.132 \\
0.013 \\
0.140\end{array}$ & Own currency's share in world reserves & $\begin{array}{c}\text { overall } \\
\text { between } \\
\text { within }\end{array}$ & 0.049 & $\begin{array}{l}0.122 \\
0.104 \\
0.057\end{array}$ & $\begin{array}{c}0.000 \\
0.000 \\
-0.130\end{array}$ & $\begin{array}{l}0.715 \\
0.625 \\
0.202\end{array}$ \\
\hline L.demeaned VIX*K openness & $\begin{array}{c}\text { overall } \\
\text { between } \\
\text { within }\end{array}$ & -0.002 & $\begin{array}{l}0.053 \\
0.005 \\
0.053\end{array}$ & $\begin{array}{l}-0.093 \\
-0.013 \\
-0.107\end{array}$ & $\begin{array}{l}0.132 \\
0.011 \\
0.141\end{array}$ & Financial Center Dummy & $\begin{array}{c}\text { overall } \\
\text { between } \\
\text { within }\end{array}$ & 0.053 & $\begin{array}{l}0.224 \\
0.210 \\
0.062\end{array}$ & $\begin{array}{c}0.000 \\
0.000 \\
-0.447\end{array}$ & $\begin{array}{l}1.000 \\
1.000 \\
0.553\end{array}$ \\
\hline L.demeaned VIX*K openness*share in world reserves & $\begin{array}{c}\text { overall } \\
\text { between } \\
\text { within }\end{array}$ & 0.000 & $\begin{array}{l}0.009 \\
0.001 \\
0.009 \\
\end{array}$ & $\begin{array}{l}-0.061 \\
-0.001 \\
-0.059\end{array}$ & $\begin{array}{l}0.084 \\
0.002 \\
0.085 \\
\end{array}$ & (Reserves)/GDP* K controls, instrumented \# & $\begin{array}{c}\text { overall } \\
\text { between } \\
\text { within }\end{array}$ & 0.001 & $\begin{array}{l}0.009 \\
0.008 \\
0.006\end{array}$ & $\begin{array}{l}-0.020 \\
-0.005 \\
-0.032 \\
\end{array}$ & $\begin{array}{l}0.082 \\
0.042 \\
0.040 \\
\end{array}$ \\
\hline
\end{tabular}

Notes: Each variable is decomposed into between $\left(\overline{x_{i}}\right)$ and within $\left(\overline{x_{i}}-x_{i}+\overline{\bar{x}}\right.$; the global mean $\overline{\bar{x}}$ is added back to make results comparable) components. 
Table 4: Hybrid model: All countries

\begin{tabular}{|c|c|c|c|c|c|c|}
\hline \multirow[t]{2}{*}{ Variables } & \multicolumn{3}{|c|}{$\begin{array}{c}\text { Group deviations } \\
\text { BMA }\end{array}$} & \multicolumn{3}{|c|}{$\begin{array}{c}\text { Group means } \\
\text { BMA }\end{array}$} \\
\hline & PIP & Posterior mean & t-stat & PIP & Posterior mean & t-stat \\
\hline Structural & & & & & & \\
\hline Dependency Ratio \# & 0.000 & 0.000 & 0.000 & 1.000 & -0.451 & -8.416 \\
\hline Aging Speed \# & 0.003 & 0.000 & -0.038 & 0.000 & 0.000 & 0.000 \\
\hline rel. Dependency Ratio*Aging Speed & 1.000 & 0.151 & 4.618 & 0.000 & 0.000 & 0.000 \\
\hline rel. Aging Speed * Dependency Ratio & 0.000 & 0.000 & 0.000 & 1.000 & 0.236 & 6.860 \\
\hline Population Growth \# & 0.347 & -0.258 & -0.667 & 1.000 & -2.655 & -8.124 \\
\hline L.Output per worker, relative to top 3 economies & 0.108 & 0.003 & 0.328 & 1.000 & 0.121 & 11.272 \\
\hline L.Relative output per worker*K openness & 0.840 & 0.025 & 1.830 & 0.000 & 0.000 & 0.000 \\
\hline Safer Institutional/Political Environment (index) \# & 0.020 & -0.001 & -0.125 & 1.000 & -0.151 & -6.302 \\
\hline \multicolumn{7}{|l|}{ Cyclical } \\
\hline GDP growth, forecast in 5 years \# & 1.000 & -0.535 & -5.025 & 0.000 & 0.000 & 0.000 \\
\hline Output Gap \# & 1.000 & -0.389 & -11.812 & 0.000 & 0.000 & 0.000 \\
\hline L.demeaned VIX & 0.201 & 0.007 & 0.461 & 0.000 & 0.000 & 0.000 \\
\hline L.demeaned VIX*K openness & 0.025 & 0.001 & 0.147 & 0.005 & 0.003 & 0.065 \\
\hline L.demeaned VIX*K openness*share in world reserves & 0.000 & 0.000 & 0.000 & 0.073 & 0.330 & 0.258 \\
\hline Commodity ToTgap & 0.007 & 0.000 & 0.069 & 0.097 & 0.031 & 0.290 \\
\hline Trade Openness & 1.000 & 0.115 & 12.227 & 1.000 & 0.032 & 4.325 \\
\hline Commodity ToTgap*Trade Openness & 0.069 & 0.007 & 0.249 & 0.473 & 0.540 & 0.849 \\
\hline $\begin{array}{l}\text { Oil and Natural Gas Trade Balance * resource temporariness \# } \\
\text { Policy }\end{array}$ & 1.000 & 0.592 & 8.272 & 1.000 & 0.331 & 3.920 \\
\hline Cyclically adjusted Fiscal Balance, instrumented \# & 0.000 & 0.000 & 0.000 & 1.000 & 0.359 & 4.538 \\
\hline L.Public Health Spending/GDP \# & 1.000 & -0.918 & -6.050 & 0.005 & -0.001 & -0.060 \\
\hline Private Credit/GDP \# & 1.000 & -0.020 & -4.941 & 0.014 & 0.000 & 0.107 \\
\hline K controls & 0.000 & 0.000 & 0.000 & 0.437 & 0.014 & 0.825 \\
\hline \multicolumn{7}{|l|}{ Initial conditions } \\
\hline L. NFA/Y & 1.000 & 0.026 & 4.160 & 1.000 & 0.069 & 10.269 \\
\hline L. NFA/Y*(dummy if NFA/Y <-60\%) & 0.505 & -0.021 & -0.905 & 0.105 & -0.006 & -0.317 \\
\hline dummy if NFA/Y $<-60 \%$ & 0.000 & 0.000 & 0.000 & 0.037 & 0.001 & 0.176 \\
\hline Own currency's share in world reserves & 0.002 & 0.000 & -0.034 & 0.972 & -0.050 & -3.052 \\
\hline Financial Center Dummy & 0.000 & 0.000 & 0.000 & 0.000 & 0.000 & 0.000 \\
\hline (Reserves)/GDP* K controls, instrumented \# & 1.000 & 0.720 & 4.979 & 0.585 & 0.419 & 1.097 \\
\hline Mean number of regressors & \multicolumn{6}{|c|}{24.000} \\
\hline Sum of probabilities of top two models & \multicolumn{6}{|c|}{0.11} \\
\hline
\end{tabular}


Table 5: Accounting for slope heterogeneity

\begin{tabular}{|c|c|c|c|c|c|c|c|c|c|c|c|c|}
\hline \multirow{2}{*}{ Variables } & \multicolumn{3}{|c|}{$\begin{array}{c}\text { Group deviations } \\
B M A\end{array}$} & \multicolumn{3}{|c|}{ Group deviations $* O E C D$} & \multicolumn{3}{|c|}{$\begin{array}{l}\text { Group means } \\
\text { BMA }\end{array}$} & \multicolumn{3}{|c|}{ Group means*OECD } \\
\hline & PIP & Posterior mean & t-stat & PIP & Posterior mean & t-stat & PIP & Posterior mean & t-stat & PIP & Posterior mean & t-stat \\
\hline Structural & & & & & & & & & & & & \\
\hline Dependency Ratio \# & 1.000 & -0.223 & -4.126 & 0.091 & 0.020 & 0.289 & 1.000 & -2.146 & -12.594 & 0.000 & 0.000 & 0.000 \\
\hline Aging Speed \# & 0.007 & -0.001 & -0.081 & 0.044 & 0.007 & 0.196 & 1.000 & 3.518 & 8.440 & 1.000 & 0.717 & 7.479 \\
\hline rel. Dependency Ratio*Aging Speed & 0.000 & 0.000 & 0.000 & 0.028 & 0.003 & 0.155 & 1.000 & -4.128 & -9.492 & 0.000 & 0.000 & 0.000 \\
\hline rel. Aging Speed * Dependency Ratio & 0.037 & 0.002 & 0.178 & 0.028 & 0.002 & 0.154 & 1.000 & 1.604 & 9.380 & 0.000 & 0.000 & 0.000 \\
\hline Population Growth \# & 0.000 & 0.000 & 0.000 & 0.998 & -1.936 & -4.453 & 1.000 & -3.886 & -9.454 & 0.000 & 0.000 & 0.000 \\
\hline L.Output per worker, relative to top 3 economies & 1.000 & 0.138 & 4.053 & 1.000 & -0.386 & -5.601 & 1.000 & 0.225 & 12.901 & 0.000 & 0.000 & 0.000 \\
\hline L.Relative output per worker*K openness & 0.874 & -0.110 & -1.984 & 1.000 & 0.335 & 3.574 & 0.000 & 0.000 & 0.000 & 0.000 & 0.000 & 0.000 \\
\hline $\begin{array}{l}\text { Safer Institutional/Political Environment (index) \# } \\
\text { Cyclical }\end{array}$ & 0.990 & -0.067 & -4.260 & 0.019 & -0.002 & -0.126 & 1.000 & -0.252 & -9.034 & 0.000 & 0.000 & 0.000 \\
\hline GDP growth, forecast in 5 years \# & 1.000 & -0.704 & -7.063 & 0.000 & 0.000 & 0.000 & 0.013 & 0.005 & 0.099 & 0.000 & 0.000 & 0.000 \\
\hline Output Gap \# & 1.000 & -0.324 & -10.393 & 0.000 & 0.000 & 0.000 & 1.000 & 0.757 & 4.157 & 0.000 & 0.000 & 0.000 \\
\hline L.demeaned VIX & 0.932 & 0.039 & 2.473 & 0.021 & -0.001 & -0.129 & 0.000 & 0.000 & 0.000 & 0.000 & 0.000 & 0.000 \\
\hline L.demeaned VIX*K openness & 0.059 & 0.003 & 0.228 & 0.017 & -0.001 & -0.118 & 0.000 & 0.000 & 0.000 & 1.000 & 2.064 & 5.108 \\
\hline L.demeaned VIX*K openness*share in world reserves & 0.000 & 0.000 & 0.000 & 0.000 & 0.000 & 0.000 & 1.000 & 17.289 & 5.137 & 0.000 & 0.000 & 0.000 \\
\hline Commodity ToTgap & 0.020 & 0.000 & -0.009 & 0.000 & 0.000 & 0.000 & 0.000 & 0.000 & 0.000 & 1.000 & -2.626 & -8.231 \\
\hline Trade Openness & 1.000 & 0.108 & 10.451 & 0.981 & 0.084 & 3.136 & 0.008 & 0.000 & 0.069 & 0.358 & 0.012 & 0.678 \\
\hline Commodity ToTgap*Trade Openness & 0.927 & 0.127 & 2.324 & 0.030 & 0.007 & 0.161 & 0.000 & 0.000 & 0.000 & 0.000 & 0.000 & 0.000 \\
\hline $\begin{array}{l}\text { Oil and Natural Gas Trade Balance * resource temporariness \# } \\
\text { Policy }\end{array}$ & 0.000 & 0.000 & 0.000 & 1.000 & 1.016 & 10.493 & 0.000 & 0.000 & 0.000 & 0.000 & 0.000 & 0.000 \\
\hline Cyclically adjusted Fiscal Balance, instrumented \# & 0.000 & 0.000 & 0.000 & 1.000 & 0.689 & 5.535 & 1.000 & 0.813 & 10.795 & 0.000 & 0.000 & 0.000 \\
\hline L.Public Health Spending/GDP \# & 1.000 & -0.978 & -6.790 & 0.005 & 0.000 & 0.009 & 0.000 & 0.000 & 0.000 & 0.000 & 0.000 & 0.000 \\
\hline Private Credit/GDP \# & 0.994 & -0.013 & -3.376 & 0.000 & 0.000 & 0.000 & 0.000 & 0.000 & 0.000 & 0.000 & 0.000 & 0.000 \\
\hline $\mathrm{K}$ controls & 0.980 & 0.049 & 3.016 & 0.011 & 0.000 & -0.089 & 1.000 & 0.035 & 4.337 & 0.000 & 0.000 & 0.000 \\
\hline Initial conditions & & & & & & & & & & & & \\
\hline L. NFA/Y & 0.043 & 0.001 & 0.204 & 0.000 & 0.000 & 0.000 & 1.000 & 0.062 & 12.857 & 0.005 & 0.000 & 0.054 \\
\hline L. NFA/Y*(dummy if NFA/Y <-60\%) & 0.000 & 0.000 & 0.000 & 0.000 & 0.000 & 0.000 & 0.000 & 0.000 & 0.000 & 0.004 & 0.001 & 0.052 \\
\hline dummy if NFA/Y $<-60 \%$ & 0.000 & 0.000 & 0.000 & 0.008 & 0.000 & -0.076 & 0.000 & 0.000 & 0.000 & 1.000 & -0.053 & -3.701 \\
\hline Own currency's share in world reserves & 0.291 & -0.013 & -0.597 & 0.651 & -0.031 & -1.177 & 1.000 & -0.111 & -8.940 & 0.000 & 0.000 & 0.000 \\
\hline Financial Center Dummy & 0.000 & 0.000 & 0.000 & 0.000 & 0.000 & 0.000 & 0.000 & 0.000 & 0.000 & 0.000 & 0.000 & 0.000 \\
\hline (Reserves)/GDP* K controls, instrumented \# & 0.963 & 0.488 & 2.685 & 0.046 & -0.048 & -0.200 & 0.000 & 0.000 & 0.000 & 1.000 & 13.749 & 6.889 \\
\hline OECD dummy & 1.000 & 0.065 & 7.985 & & & & & & & & & \\
\hline $\begin{array}{l}\text { Mean number of regressors } \\
\text { Sum of probabilities of top two models }\end{array}$ & & & & & $\begin{array}{l}40.000 \\
0.200\end{array}$ & & & & & & & \\
\hline
\end{tabular}

Notes: PIP: Posterior Inclusion Probability. 'BMA': Bayesian Model Averaging. $t$-stat corresponds to posterior mean divided by posterior standard deviation. 'L.': denotes one

year lag. Variables followed by \# are constructed relative to a (GDP-weighted) country sample average, in each year. 
Table 6: Determinants of the current account: Pooled OLS estimator

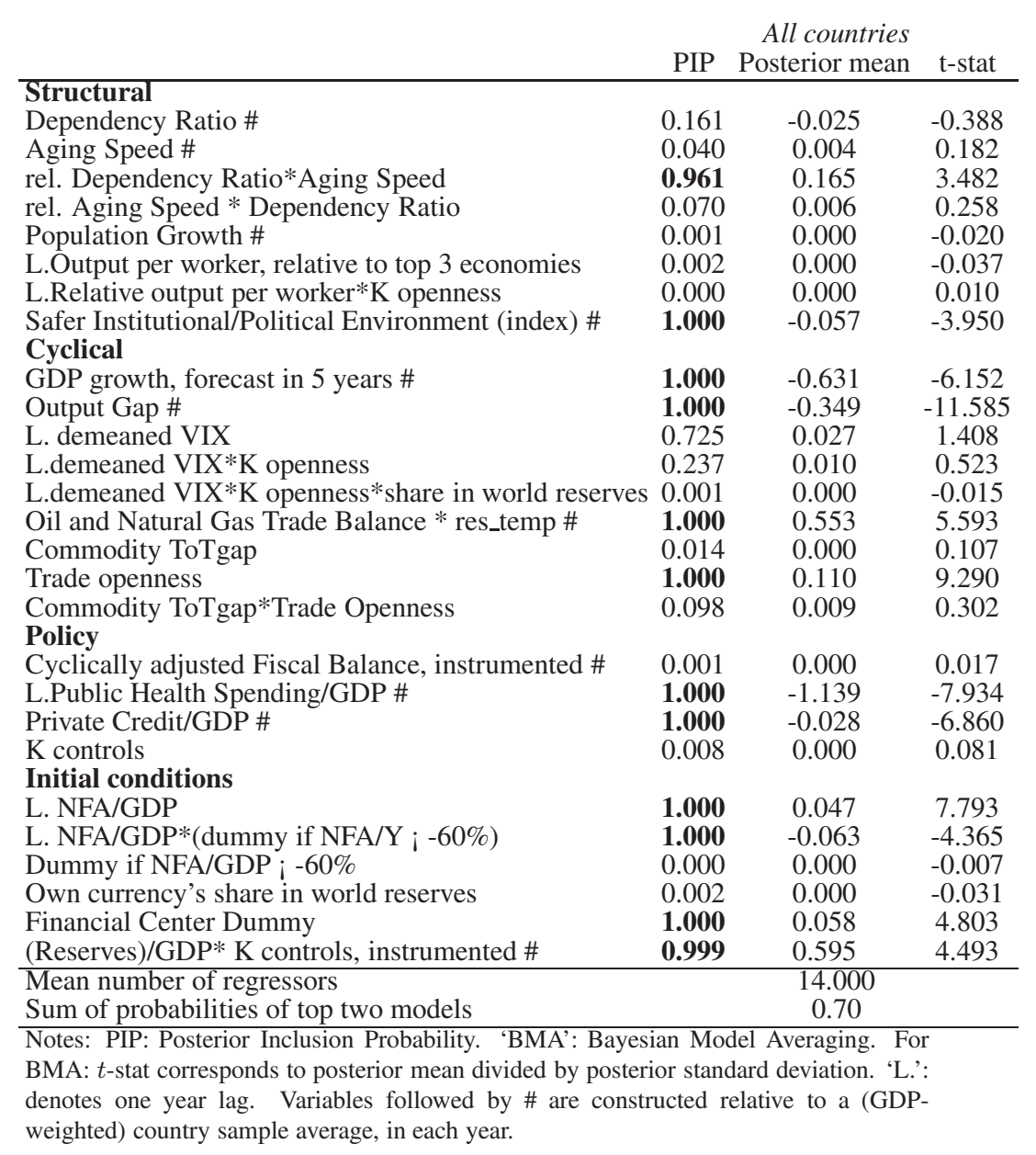


Table 7: Predicting current account balances

Pooled Hybrid

(1) Group dev. Group dev.*OECD Group av.

Group av.*OECD

\section{Structural}

Dependency Ratio \#

Aging Speed \#

rel. Dependency Ratio*Aging Speed

rel. Aging Speed * Dependency Ratio

Population Growth \#

L.Output per worker, relative to top 3 economies

L.Relative output per worker*K openness

Safer Institutional/Political Environment (index) \#

\section{Cyclical}

GDP growth, forecast in 5 years \#

Output Gap \#

L.demeaned VIX

L.demeaned VIX $*$ K openness

L.demeaned VIX*K openness*share in world reserves

Commodity ToTgap

Trade Openness

Commodity ToTgap*Trade Openness

Oil and Natural Gas Trade Balance * resource temporariness \#

-0.060
$(0.058)$
-0.062
$(0.131)$
0.219
$(0.140)$
$0.094 * *$
$(0.045)$
$-0.845 * * *$
$(0.326)$
0.025
$(0.024)$
$0.056 * *$
$(0.024)$
$-0.098^{* * *}$
$(0.019)$

$-0.145 * *$

$(0.062)$

$(0.019)$

$-0.459 * * *$
$(0.104)$
$-0.397 * * *$
$(0.031)$
0.051
$(0.035)$
-0.000
$(0.040)$
-0.113
$(0.077)$
-0.027
$(0.021)$
$0.047 * * *$
$(0.011)$
$0.322 * * *$
$(0.083)$
$0.441 * * *$
$(0.085)$

$0.184 * *$

(0.093)

$-0.120^{*}$

$(0.067)$

$-0.086 * * *$

(0.026)

$\begin{array}{cc} & -1.063 * \\ & (0.614) \\ & 1.904 \\ & (1.302) \\ & -2.297 * \\ & (1.391) \\ & 0.803 \\ & (0.576) \\ -1.756 * * & -2.023 \\ (0.752) & (1.319) \\ -0.383^{* * *} & 0.096 * * * \\ (0.116) & (0.034) \\ 0.309 * * * & \\ (0.101) & \\ & -0.172 * * * \\ & (0.044)\end{array}$

$-0.728 * * *$

(0.161)

$-0.340 * * *$

(0.079)

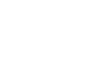

$0.377 * * *$

(0.088)

$-0.563 * * *$

(0.110)

$-0.006$

(0.004)

0.008

(0.010)

$0.018 * *$

(0.008)

$-0.006$

$(0.015)$

$-0.000$

(0.004)

$-0.049 * * *$

(0.016)

$0.017 *$

(0.009)

0.209

Financial Center Dummy

(Reserves)/GDP* K controls instrumented \#

$0.068 * *$
$(0.029)$
$0.117 * *$
$(0.059)$

(0.059)

$-1.146 * * *$

$(0.274)$

$-0.021 * *$

(0.010)

$0.044^{*}$

(0.024)

$0.116^{* *}$

(0.051)

$1.093 * * *$

(0.119)

$0.771 * * * \quad 0.708 * * *$

4.041

(4.553)

0.913

(0.912)

$-1.256$

(1.145)

(0.171)
0.043

(0.356)

(0.244)

OECD dummy

Notes: $* * * \mathrm{p}<0.01 * * \mathrm{p}<0.05 * \mathrm{p}<0.10$. Column (1) is estimated using the Prais-Winsten transformation to deal with firstorder autocorrelation. Estimation of the hybrid model is done using a random effects estimator with standard errors clustered at the country level. 1174 observations. 
Table 8: Group means when controlling for unobserved country heterogeneity

\begin{tabular}{|c|c|c|c|c|}
\hline \multirow[t]{2}{*}{ Variables } & \multicolumn{2}{|c|}{ Group means } & \multicolumn{2}{|c|}{ Group means $* \mathrm{OECD}$} \\
\hline & PIP & Sign & PIP & Sign \\
\hline \multicolumn{5}{|l|}{ Structural factors } \\
\hline Dependency Ratio \# & 0.294 & -1 & 0.310 & 1 \\
\hline Aging Speed \# & 0.312 & -1 & 0.542 & 1 \\
\hline rel. Dependency Ratio*Aging Speed & 0.364 & -1 & 0.545 & 1 \\
\hline rel. Aging Speed * Dependency Ratio & 0.296 & -1 & 0.339 & 1 \\
\hline Population Growth \# & 0.234 & -1 & 0.277 & 1 \\
\hline L.Output per worker, relative to top 3 economies & 0.600 & 1 & 0.426 & 1 \\
\hline L.Relative output per worker* K openness & 0.577 & 1 & 0.427 & 1 \\
\hline Safer Institutional/Political Environment (index) \# & 0.687 & -1 & 0.319 & 1 \\
\hline \multicolumn{5}{|l|}{$\begin{array}{l}\text { Cyclical factors } \\
\text { Cyst }\end{array}$} \\
\hline GDP growth, forecast in 5 years \# & 0.365 & 1 & 0.343 & -1 \\
\hline Output Gap \# & 0.139 & -1 & 0.271 & -1 \\
\hline L.demeaned VIX & 0.236 & 1 & 0.596 & 1 \\
\hline L.demeaned VIX $* K$ openness & 0.210 & -1 & 0.453 & 1 \\
\hline L.demeaned VIX*K openness*share in world reserves & 0.347 & 1 & 0.346 & 1 \\
\hline Commodity ToTgap & 0.474 & 1 & 0.414 & -1 \\
\hline Trade Openness & 0.497 & 1 & 0.796 & 1 \\
\hline Commodity ToTgap*Trade Openness & 0.248 & -1 & 0.405 & 1 \\
\hline $\begin{array}{l}\text { Oil and Natural Gas Trade Balance * resource temporariness \# } \\
\text { Policy }\end{array}$ & 0.940 & 1 & 0.777 & -1 \\
\hline Cyclically adjusted Fiscal Balance, instrumented \# & 0.607 & 1 & 0.275 & 1 \\
\hline L.Public Health Spending/GDP \# & 0.675 & -1 & 0.766 & 1 \\
\hline Private Credit/GDP \# & 0.568 & 1 & 0.302 & -1 \\
\hline $\mathrm{K}$ controls & 0.343 & 1 & 0.251 & -1 \\
\hline \multicolumn{5}{|l|}{ Initial conditions } \\
\hline L. NFA/Y & 0.863 & 1 & 0.352 & -1 \\
\hline L. NFA/Y*(dummy if NFA/Y <-60\%) & 0.261 & 1 & 0.273 & -1 \\
\hline dummy if NFA/Y $<-60 \%$ & 0.321 & -1 & 0.284 & -1 \\
\hline Own currency's share in world reserves & 0.485 & -1 & 0.482 & -1 \\
\hline Financial Center Dummy & 0.305 & 1 & 0.305 & 1 \\
\hline (Reserves)/GDP* K controls, instrumented \# & 0.543 & 1 & 0.339 & 1 \\
\hline OECD dummy & & & 0.453 & -1 \\
\hline
\end{tabular}

Notes: PIP: Posterior Inclusion Probability. Sign: ‘1’: positive;'-1’: negative. 'L.’: denotes one year lag. Variables followed by \# are constructed relative to a (GDP-weighted) country sample average, in each year. 
Figure 1: Median absolute CABs residuals

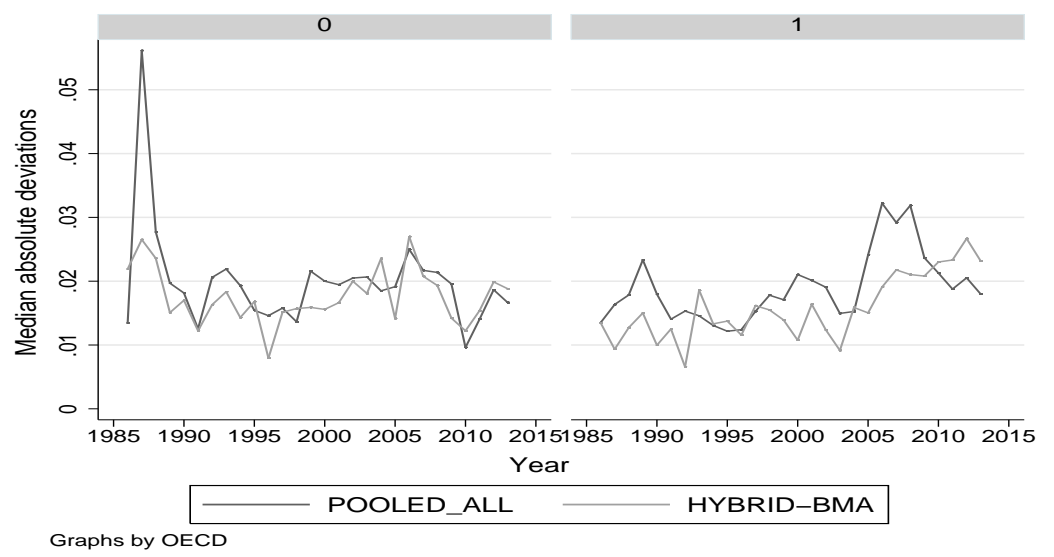

